Document No. Y/DK-2152 Rev. 1

\title{
Filter Paper: Solution to High Self-Attenuation Corrections in HEPA Filter Measurements
}

\author{
R. B. Oberer \\ N. B. Harold \\ C. A. Gunn \\ M. Brummett \\ L. G. Chiang
}

October 2005

\author{
Prepared by the \\ Y-12 National Security Complex \\ P.O. Box 2009, Oak Ridge Tennessee 37831-8169 \\ Managed by \\ BWXT Y-12, L.L.C. \\ For the \\ U.S. DEPARTMENT OF ENERGY \\ Under contract DE-AC05-00OR22800
}




\section{DISCLAIMER}

This work of authorship and those incorporated herein were prepared by Contractor as accounts of work sponsored by an agency of the United States Government. Neither the United States Government nor any agency thereof, nor Contractor, nor any of their employees, makes any warranty, express or implied, or assumes any legal liability or responsibility for the accuracy, completeness, use made, or usefulness of any information, apparatus, product, or process disclosed, or represents that its use would not infringe privately owned rights. Reference herein to any specific commercial product, process, or service by trade name, trademark, manufacturer, or otherwise, does not necessarily constitute or imply its endorsement, recommendation, or favoring by the United States Government or any agency or Contractor thereof. The views and opinions of authors expressed herein do not necessarily state or reflect those of the United States Government or any agency or Contractor thereof. 
An 8 by 8 by 6 inch High Efficiency Particulate Air (HEPA) filter was measured as part of a uranium holdup survey in June of 2005 as it has been routinely measured every two months since 1998. Although the survey relies on gross gamma count measurements, this was one of a few measurements that had been converted to a quantitative measurement in 1998. The measurement was analyzed using the traditional Generalized Geometry Holdup (GGH) approach, ${ }^{1}$ using HMS3 software, ${ }^{2}$ with an area calibration and selfattenuation corrected with an empirical correction factor of 1.06. A result of 172 grams of ${ }^{235} \mathrm{U}$ was reported. The actual quantity of ${ }^{235} \mathrm{U}$ in the filter was approximately $1700 \mathrm{~g}$.

Because of this unusually large discrepancy, the measurement of HEPA filters will be discussed. Various techniques for measuring HEPA filters will be described using the measurement of a 24 by 24 by 12 inch HEPA filter as an example. A new method to correct for self attenuation will be proposed for this measurement Following the discussion of the 24 by 24 by 12 inch HEPA filter, the measurement of the 8 by 8 by 6 inch will be discussed in detail.

\section{HEPA filter construction}

Understanding the construction of a HEPA filter is necessary for an accurate measurement. The construction of the HEPA filter is shown in Figure 1. High density, 0.015 inch thick, filtering media of submicron glass fibers is folded into a closely pleated pack with pleats evenly spaced by corrugated, 0.0015 inch thick, aluminum separators which support the media and allow air to flow through with minimum resistance. ${ }^{3}$ There is about $2 \mathrm{~kg}$ of filter paper media and $4.5 \mathrm{~kg}$ of aluminum in the 24 by 24 by 12 inch HEPA filter. The accumulation of material is uniformly deposited within the volume of the filter.

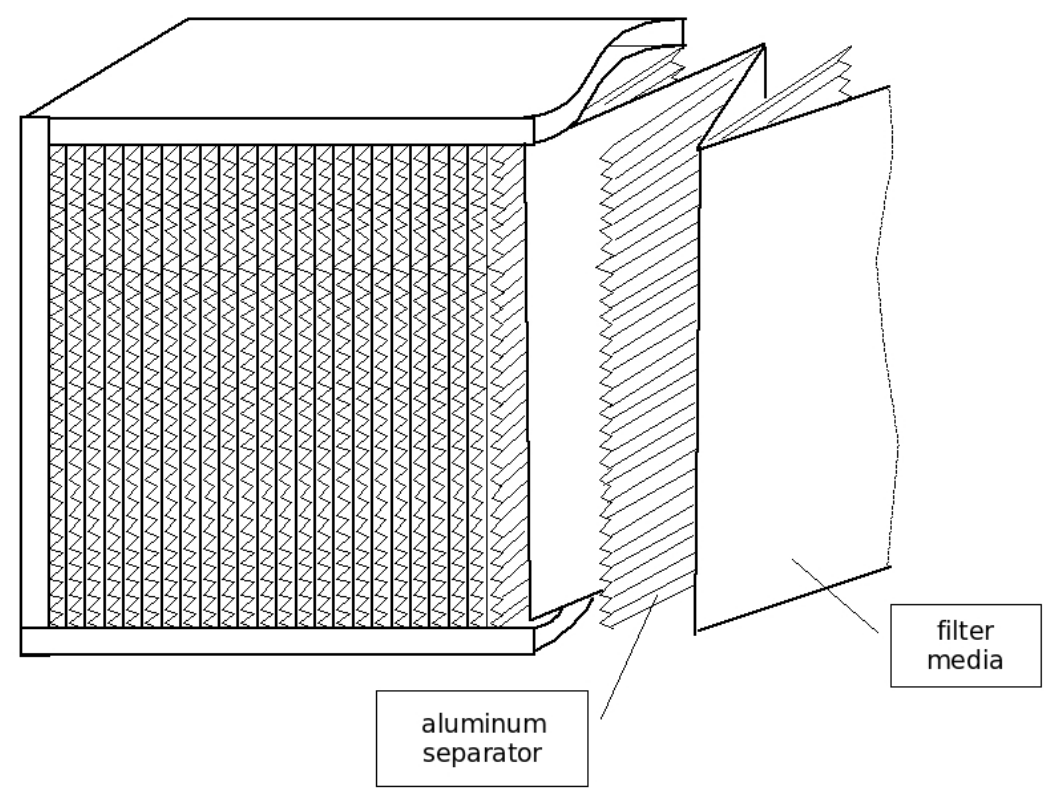

Figure 1. Drawing of the construction of a high efficiency particulate air (HEPA) filter.

\footnotetext{
${ }^{1}$ P. A. Russo, "Gamma-Ray Measurements Of Holdup Plant-Wide: Application Guide For Portable, Generalized Approach,” Los Alamos National Laboratory report LA-14206 (May 2005).

${ }^{2}$ S.E. Smith, K.A. Thompson, R.N. Ceo, "Holdup Measurement System 3 (HMS3) User’s Guide and Software Documentation, Y/DK-1104 (1997).

${ }^{3}$ STD.ASME AG-1-ENGL 1997, p393.
} 


\section{4 by 24 by 12 inch HEPA filter}

First a straight forward measurement of a HEPA filter, removed from the housing, will be described. This filter was a 24 by 24 by 12 inch HEPA filter. It was measured on two separate occasions, once in March 2005 and then again in June 2005. The measurement time was 100 seconds for both sets of the measurements. Three different physical detector-filter distances were used and several analytical approaches were used to analyze the data. The variation in results between these methods provides an interesting example of how sampling and modeling contribute to uncertainty.

In March, the filter was measured with a NaI detector and DigiDart MCA (DD106-100093) at a distance of 16 inches, using an area calibration. The spectra were processed using both NaIGEM ${ }^{4}$ and the two regionof-interest (ROI) approach. Self attenuation was estimated using both a transmission measurement and directly from the density thickness result. In June, the filter was remeasured using $\mathrm{NaI}$ detector and microNomad MCA (M328-100077). This time the detector was placed at 10 inches for an area calibration and then at 60 inches for a point calibration.

The area model has the advantage of a closer detector to material distance which increases the count rate and reduces background interference. The disadvantage is that implicit in the model is the assumption that the material is uniformly distributed in the area. If the material is actually concentrated in the center of the filter, for example, the measurement will be biased high. In addition, the aluminum separators collimate the gamma rays from the material between them. This collimation effect makes the area calibration less valid. The point model reduces the bias produced by the non-uniform distribution of the material but the tradeoff is that the count rate is reduced and background becomes more significant. The increased distance also reduces the collimation effect of the aluminum separators. Frequently, high background or other physical constraints limit the feasibility of the point measurement.

\section{Physical measurement and spectrum processing}

Table 1 shows the results of the three measurement configurations. Both sides (front and back) of the filter were measured each time. The spectrum for the first measurement at 16 inches was analyzed with both the two-ROI method as well as NaIGEM. These two methods of spectrum processing are not directly comparable. The NaIGEM count rate is determined by dividing the NaIGEM reported enrichment by the calibration constant. ${ }^{5}$ The calibration constant used was 0.0015904 . The count rate represents counts from 143.77, 163.37, 182.57, 185.72, 194.94, 202.1, and $205.33 \mathrm{keV}$ gamma rays. The ROI used in the two ROI approach extends from $161 \mathrm{keV}$ to $211 \mathrm{keV}$. This ROI represents the $186 \mathrm{keV}$ peak. The second ROI extends from $241 \mathrm{keV}$ to $291 \mathrm{keV}$. It is used as an estimate the Compton continuum in the first ROI. Although the NaIGEM approach reports a larger uncertainty, it is unlikely that it is truly larger. An interesting factor is that NaIGEM detected no room background. At 16 inches, the front face of the filter just fills the detector field of view. The rest of the filter begins to fall outside the field of view.

In June the filter was measured as an area at 10 inches and as a point at 60 inches. Only the two ROI method of spectrum processing was used. The point model has the advantage of better sampling. The entire filter is detected near the center of the detector field of view. A finite source correction is also applied to correct for the extent that the width of the point source extends beyond the center of the detector field of view. The estimated width of the point source becomes another source of uncertainty. In the area measurement, the center of the filter is weighted higher from the radial response of the detector. The amount of material in the center of the filter will bias the measurement. This is a delimitation error caused by the instrument according to sampling theory. ${ }^{6}$ A comparison of the 10 inch and 16 inch area

\footnotetext{
${ }^{4}$ R. Gunnink, “A Guide for Using NaIGEM, PC Version 1.51b for DOS and Windows,” December 2002. Although NaIGEM is designed to measure enrichment, only the spectrum processing capability was used for these measurements.

${ }^{5}$ This type of spectrum processing has never previously been used for holdup measurements. The method will be described in detail in another paper.

${ }^{6}$ P. Gy, “Sampling for Analytical Purposes,” John Wiley, New York, 1996.
} 
measurement suggests that the material might be concentrated in the center of the filter. However this comparison could be the result of the collimation effect of the separators or, more likely, to the filter falling outside the detector field of view. Because the count rate is lower for the point measurement, the uncertainty is greater. This uncertainty however does not include the sampling bias.

Table 1. Net count in the $186 \mathrm{keV}$ peak for filter and background with uncertainty for 100 second counts of the 24 by 24 inch filter in March 2005 and June 2005. The gram quantity results are shown in Table 3.

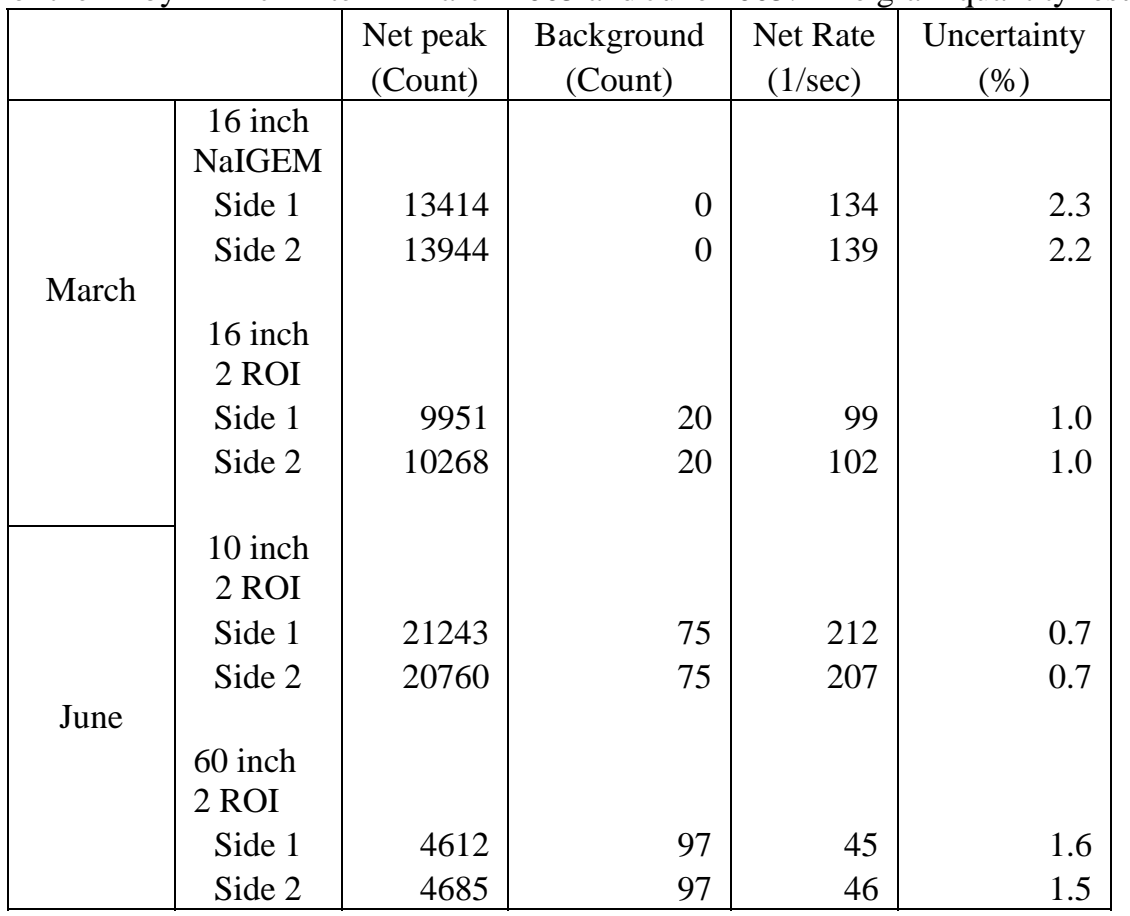

\section{Self attenuation correction}

\section{Measured transmission}

Four approaches were used to correct for material self attenuation. These four approaches are measured transmission, density thickness, solution, and HMS3 software. The measured transmission approach was used on all of the measurements of the 24 by 24 filter. In this approach, the transmission $\boldsymbol{T}$ is measured and the self-attenuation correction calculated as

$$
C F_{\text {self }}=\frac{-\ln (T)}{1-T} \approx \frac{1}{\sqrt{T}}
$$

A Los Alamos technique was used to measure transmission. In this clever technique another filter is used as a transmission source. It has the advantage of eliminating the need to bring a transmission source. In addition, because the material in the two filters is distributed similarly, the transmission is sampled more appropriately than a point source transmission. First the filter is measured, then the filter and transmission source are measured together. Next, the filter is removed and the transmission source is measured alone. 


\section{Density thickness}

In the density thickness approach, ${ }^{7}$ a calculated transmission is used to correct for self attenuation. The self attenuation correction factor is then solved for the true density thickness $\left(\rho_{U 235} X_{m}\right)$ from the measured density thickness $K_{a} R$. The true density thickness of ${ }^{235} \mathrm{U}$ is then

$\left(\rho_{U 235} x_{m}\right)=-\frac{1}{\mu^{\prime}} \ln \left[1-\mu^{\prime}\left(K_{a} R\right)\right]$. A “normalizing” mass attenuation coefficient must be calculated as $\mu^{\prime}=\frac{1.456 f_{U}+\mu_{\text {mat }}\left(1-f_{U}\right)}{\varepsilon f_{U}}$ from the mass attenuation coefficient of uranium $\mu_{U}\left(1.456 \mathrm{~cm}^{2} / \mathrm{g}\right)$, the fraction of the uranium in the filter by weight $\boldsymbol{f}_{U}$, the mass attenuation coefficient of the material other than uranium $\mu_{\text {mat }}$, and the enrichment $\varepsilon$. The disadvantage of this approach is that the fraction of uranium and the enrichment are typically not well known in anything other than pure materials.

Table 2. Parameter values for self attenuation. The units for the mass-attenuation coefficients $\mathrm{are} \mathrm{cm}^{2} / \mathrm{g}$.

\begin{tabular}{|c|r|}
\hline Variable & Value \\
\hline$\mu^{\prime}$ & 1.96 \\
\hline $\boldsymbol{f}_{\boldsymbol{U}}$ & 0.2 \\
\hline$\mu_{\text {mat }}$ & 0.125 \\
\hline$\varepsilon$ & 0.37 \\
\hline
\end{tabular}

\section{Solution approach}

The density thickness approach is appropriate when the fraction of uranium remains constant. An example is the accumulation of $\mathrm{U}_{3} \mathrm{O}_{8}$ collecting on the bottom of a duct. In the case of a filter, the amount of filter media remains constant with the amount of uranium bearing material varying. This situation is similar to the measurement of a uranium solution. ${ }^{8}$ This approach can be applied by calculating an expected count rate from the mass of uranium in the filter. The expected count rate is $R=-\frac{\varepsilon m_{U}}{A k_{a}} \frac{(1-T)}{\ln (T)}$, where $\varepsilon m_{U}$ is the mass of ${ }^{235} \mathrm{U}, A$ is the area of the filter, $k_{a}$ is the area calibration constant. The transmission, $e^{-\mu \rho x}$, is also a function of the mass of uranium, where $\mu \rho x=\frac{\mu_{U} m_{U}+\sum \mu_{i} m_{i}}{A}$. Note that the mass of aluminum and paper remains constant whereas the mass of oxygen is proportional to the mass of uranium. The equation cannot be solved for uranium mass. Instead a calibration curve is plotted from the equation. A plot of this theoretical calibration is shown in Figure 2.

\footnotetext{
${ }^{7}$ P.A. Russo, T.R. Wenz, S.E. Smith, J.F. Harris, “Achieving Higher Accuracy in the Gamma-Ray Spectroscopic Assay of Holdup,” Los Alamos National Laboratory report LA-13699-MS (September 2000).
}

${ }^{8}$ P. A. Russo, T. R. Wenz, and K. D. Veal, “In Situ Measurement of Process Solution Inventory of ${ }^{235} \mathrm{U}$," Los Alamos National Laboratory report LA-UR-00-2470 (June 2000). 


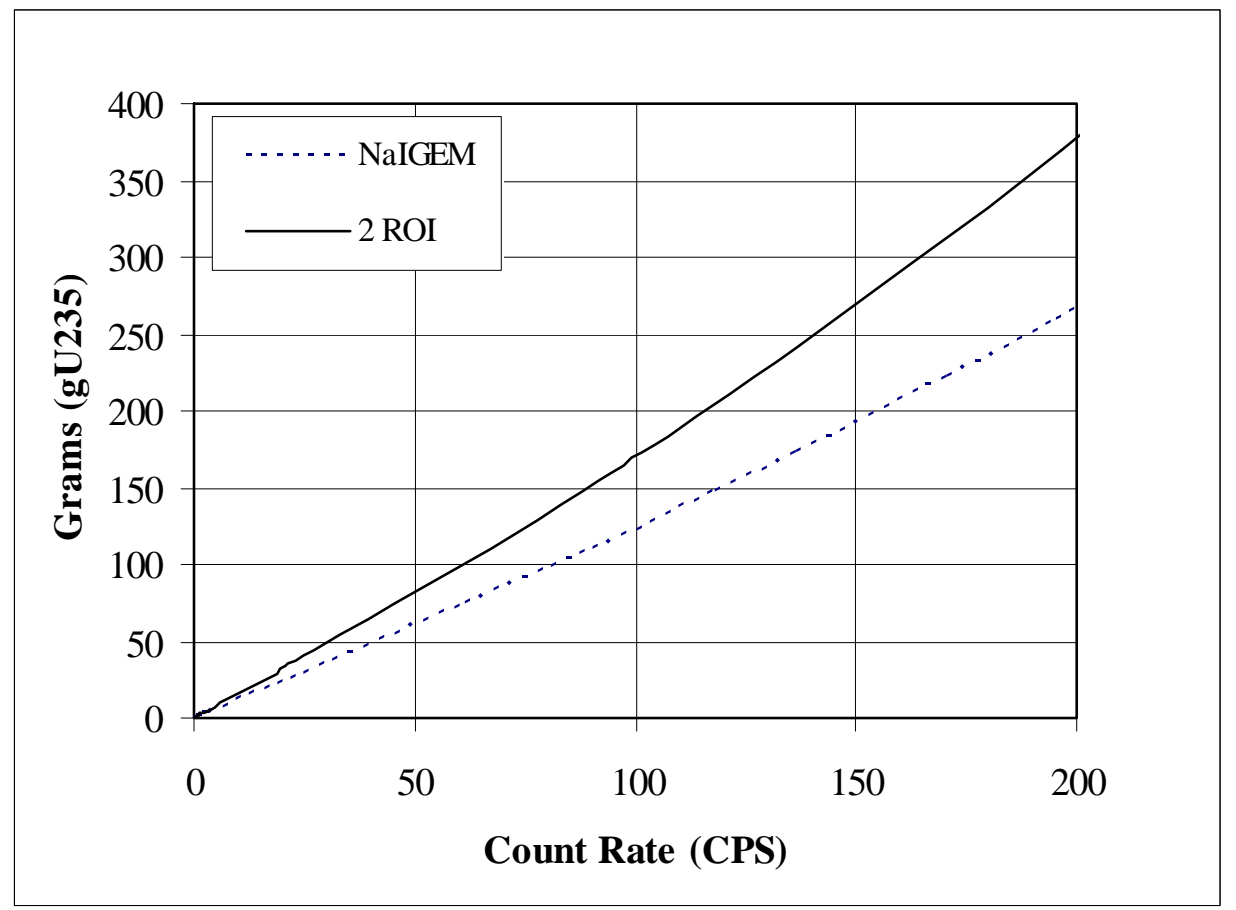

Figure 2. Calibration curve for the 24 by 24 inch filter for both the NaIGEM and 2 ROI method of spectrum analysis.

\section{HMS3 approach}

Historically at Y-12, HEPA filters were measured with HMS3 with an empirical correction factor. A correction factor was calculated by dividing a measurement of a filter on the segmented gamma scanner (SGS) with a holdup measurement of the same filter. The advantage of this approach is that it corrects for biases other than self attenuation. On the other hand, it assumes the SGS measurement is correct, and it also does not take into account the nonlinear nature of self attenuation. Because of this deficiency, a self attenuation correction was also made to the result using a separate program. The separate program is either an HMS3 add-in, Self-Attenuation v1.00 written in 2000. 
Table 3. Results of various analytical techniques to correct for self attenuation. A finite source correction of 1.2997 was also applied to the point source.

\begin{tabular}{|c|c|c|c|c|c|c|c|c|}
\hline & & $\begin{array}{l}\text { Calibration } \\
\left(\mathrm{sec} \cdot \mathrm{g} / \mathrm{cm}^{2}\right)\end{array}$ & $\begin{array}{c}\text { Average } \\
\text { Net Rate } \\
(1 / \mathrm{sec})\end{array}$ & $\begin{array}{c}\text { Finite } \\
\text { source } \\
\text { correction }\end{array}$ & $\begin{array}{l}\text { Empirical } \\
\text { Correction }\end{array}$ & $\begin{array}{l}\text { Self Atten } \\
\text { Correction }\end{array}$ & $\begin{array}{l}\text { Density } \\
\text { Thickness } \\
\left(\mathrm{g} / \mathrm{cm}^{2}\right)\end{array}$ & $\begin{array}{c}\text { U-235 } \\
\text { (g) }\end{array}$ \\
\hline \multirow{2}{*}{ March } & $\begin{array}{r}16 \text { inch GEM } \\
\text { Transmission } \\
\text { Density } \\
\text { Calibration }\end{array}$ & 2.813E-04 & $\begin{array}{l}137 \\
137 \\
137\end{array}$ & & & $\begin{array}{l}1.0851 \\
1.1183\end{array}$ & $\begin{array}{l}0.0418 \\
0.0431\end{array}$ & $\begin{array}{l}155 \\
160 \\
174\end{array}$ \\
\hline & $\begin{array}{r}16 \text { inch } \\
2 \text { ROI } \\
\\
\text { Transmission } \\
\text { Density } \\
\text { Calibration }\end{array}$ & 3.778E-04 & $\begin{array}{l}101 \\
101 \\
101 \\
\end{array}$ & & & $\begin{array}{l}1.0851 \\
1.1170\end{array}$ & $\begin{array}{l}0.0414 \\
0.0426\end{array}$ & $\begin{array}{l}154 \\
158 \\
173\end{array}$ \\
\hline \multirow{2}{*}{ June } & $\begin{array}{r}10 \text { inch } \\
\text { Transmission } \\
\text { HMS3 }\end{array}$ & 2.149E-04 & $\begin{array}{l}209 \\
209\end{array}$ & & 1.0750 & $\begin{array}{l}1.1929 \\
1.0866\end{array}$ & $\begin{array}{l}0.0536 \\
0.0525 \\
\end{array}$ & $\begin{array}{l}199 \\
195\end{array}$ \\
\hline & $\begin{array}{r}60 \text { inch } \\
\text { Transmission } \\
\text { HMS3 }\end{array}$ & 8.472E-05 & $\begin{array}{l}46 \\
46\end{array}$ & $\begin{array}{l}1.2997 \\
1.2997\end{array}$ & 1.0750 & $\begin{array}{l}1.2384 \\
1.0720\end{array}$ & $\begin{array}{l}0.0063 \\
0.0058\end{array}$ & $\begin{array}{l}146 \\
136\end{array}$ \\
\hline
\end{tabular}

The final results are shown in the last column of Table 3. For area measurements, the density thickness is multiplied by the surface area of the filter $\left(3716 \mathrm{~cm}^{2}\right)$ to arrive at grams of ${ }^{235} \mathrm{U}$. The average value is $165 \mathrm{~g}$ of ${ }^{235} \mathrm{U}$. The values vary from a minimum of $136 \mathrm{~g}$ to a maximum of $199 \mathrm{~g}$ of ${ }^{235} \mathrm{U}$. The variation between methods is much greater than the variation between the front and back measurement using the same method. The variation between measurements can be reduced by correcting some subtle mistakes. First the 16 inch standoff is too large. Only the front face of the filter fills the detector field of view. The 10 inch distance is probably a better choice for an area model. Second, the 60 inch standoff for the point model was the distance from the face of the detector to the front face of the filter. The filter is 12 inches thick. Therefore a more appropriate place to measure the distance would be somewhere inside the filter. A first rough guess might be to the center of the filter, making the actual standoff 66 inches. This distance would increase the estimate by about $20 \%$.

Nevertheless, all of the measurement approaches are valid. Even in the most straight forward measurement, the model used, including the self attenuation correction, and the instrument delimitation (sampling) uncertainty generates significant variation in the results.

\section{Detailed description of the June measurement of the 8 by 8 by 6 inch HEPA filter}

The second filter is constructed similarly to the first except that the face is 8 by 8 inches and the filter is 6 inches thick. The filter was measured in place in June 2005 with a 30 second count time as it was on a routine basis. The filter was measured as an area at a 3 inch distance from the filter inlet housing as shown in Figure 3. This orientation was chosen because it was believed that the uranium material accumulated on the inlet face of the filter. It was later learned that the uranium material accumulated fairly uniformly throughout the volume of the filter. The two ROI method of spectrum processing was used. The net counts from the filter and background from the 30 second count are shown in Table 4. The original measurement was analyzed using the traditional GGH approach with self-attenuation corrected with an empirical correction factor of 1.06 . The result reported was $170 \mathrm{~g}{ }^{235} \mathrm{U}$. The actual quantity was $1700 \mathrm{~g}$. 
The cause of the factor of 10 underestimate of the measurement was the combination of failing to correct for non-ideal geometry combined with the effects of high self attenuation. At the time the measurement was established in 1998, GGH did not include a geometry correction, and self attenuation corrections were typically considered insignificant. From an historical perspective GGH was invented to measure holdup which was material remaining in process equipment after cleanout. Under these conditions self attenuation is rarely significant. In recent times, GGH has been expanded to measure larger quantities of material. In 2000 Los Alamos proposed a geometry correction for point and line geometries and a self attenuation correction. $^{9}$ However, there was no geometry correction for area calibrations. A more generalized geometry correction was subsequently proposed by $\mathrm{Y}-12 .^{10}$

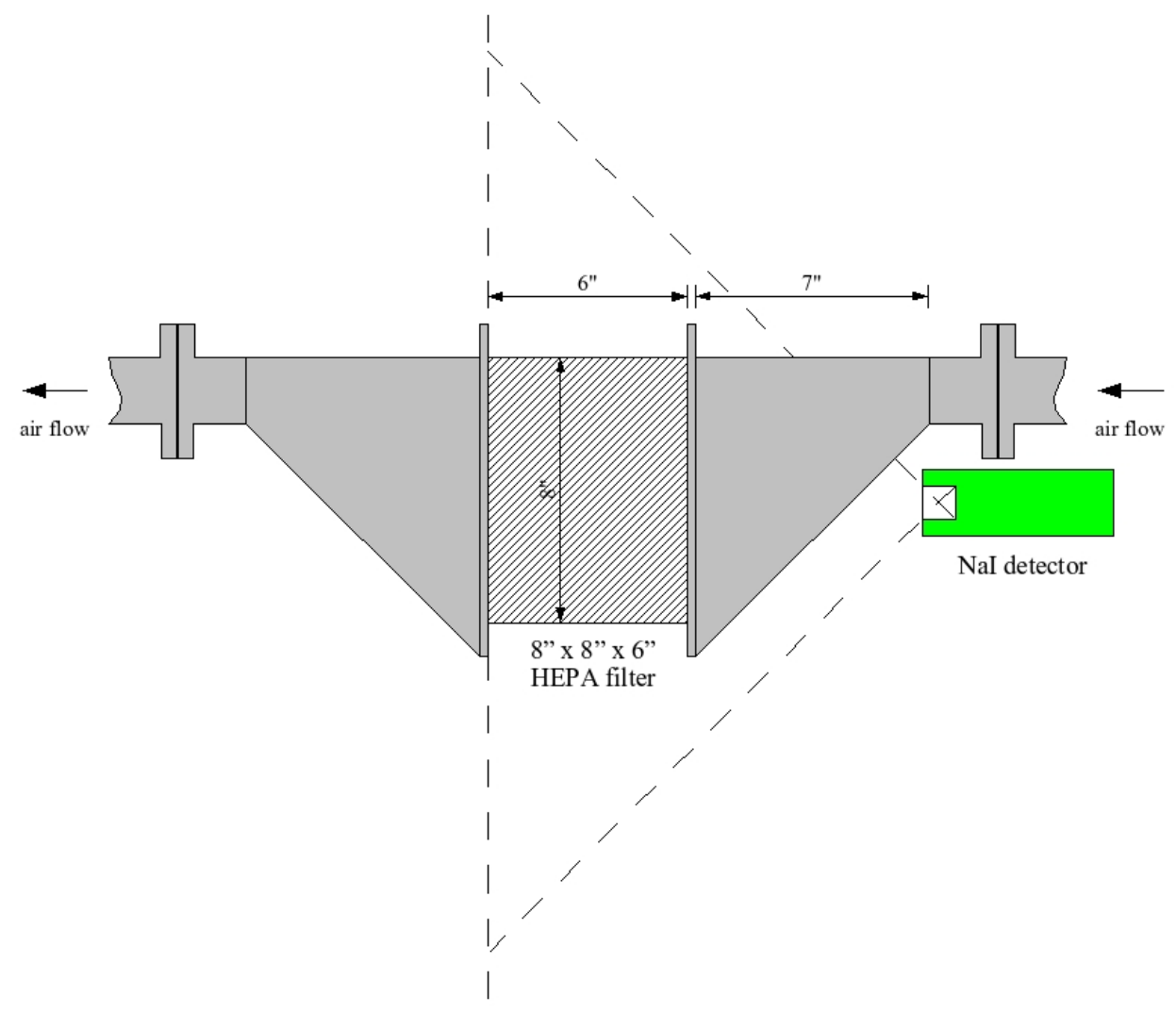

Figure 3. Measurement geometry of the HEPA filter.

\section{Geometry Correction}

The geometry of the measurement is shown in Figure 3. When the measurement was first performed in 1998, it was believed that the uranium material accumulated on the front surface of the filter. The orientation of the detector was thought to be the only valid orientation. The filter housing constrained the filter-to-detector distance. An area calibration was chosen. The requirement for an area calibration is that the material fill the detector field of view. For a volume geometry, the volume must fill the detector field of view as well. The detector field of view is defined by the radial response of the detector as shown in

\footnotetext{
${ }^{9}$ Note 5 .

${ }^{10}$ C.A. Gunn, R.B. Oberer, L.G. Chiang, R.N. Ceo, "A Generalized Finite Source Calibration Factor: A Natural Improvement to the Finite Source Correction Factor for Uranium Holdup Measurements,” Y/DX2525, (January 2002).
} 
Figure 4. This radial response is taken with a source to detector distance of $40 \mathrm{~cm}$. The field of view is a cone, but the surface of the cone is not sharply defined. As a rule of thumb, the field of view of the detector is from 60/40 to 70/40 times the source-to-detector distance. As shown in Figure 4, the detector response is virtually zero at either \pm 30 or $\pm 35 \mathrm{~cm}$ from the center. The detector face was about 8 inches from the front face of the filter, and about 14 inches from the back face of the filter. The detector field of view therefore extends beyond both the front and back surfaces of the filter.

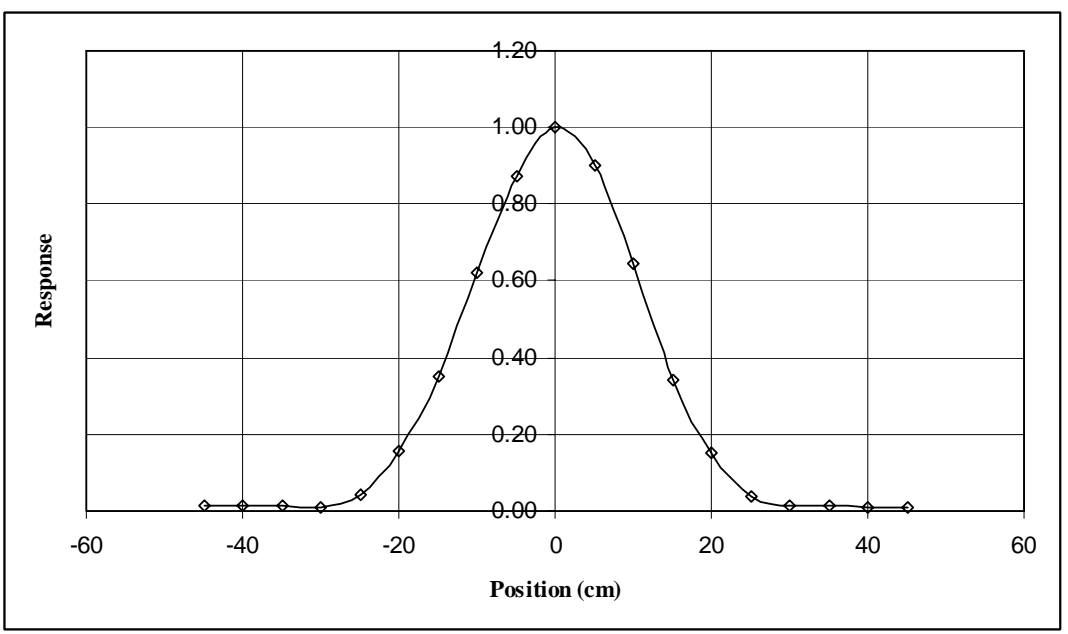

Figure 4. Radial response of MCA/Detector pair N302/100059.

The GGH approach as currently taught by Los Alamos and implemented in HMS4 does not include a geometry correction for area calibrations. The geometry correction is only used for point and line geometries. Furthermore, the Los Alamos implementation of the geometry correction is only accurate for small deviations from ideal point and line geometries. ${ }^{11}$

There are several methods to determine a geometry correction from a non-ideal geometry. The first is an empirical approach. The count rate of the detector when the filter fills the detector field of view can be compared to the count rate of the detector in the non-ideal position. The correction factor is then the ratio of the ideal to non-ideal count rates. Such a measurement was made on August 29 when the filter was removed. The correction factor was about 1.8. When an empirical measurement of the correction factor is not available, the ideal and non-ideal geometries can be simulated with a Monte Carlo simulation. Finally, the geometry factor can be calculated directly from the radial response of the detector as proposed by Y-12 in $2003 .{ }^{12}$

Table 4. Corrected count rate results from the June measurement of the 8 by 8 by 6 inch HEPA filter.

\begin{tabular}{|l|c|c|c|c|c|}
\hline 30 sec count time & $\begin{array}{c}\text { Net } \\
\text { peak } \\
\text { (Count) }\end{array}$ & $\begin{array}{c}\text { Background } \\
\text { (Count) }\end{array}$ & $\begin{array}{c}\text { Equipment } \\
\text { Correction }\end{array}$ & $\begin{array}{c}\text { Geometric } \\
\text { Correction }\end{array}$ & $\begin{array}{c}\text { Net Rate } \\
(1 / \mathrm{sec})\end{array}$ \\
\hline Background subtracted & 30893 & 1150 & 1.44 & 1.00 & 1456 \\
No background & 30893 & 0 & 1.44 & 1.00 & 1483 \\
Geometry correction & 30893 & 0 & 1.44 & 1.5 & 2224 \\
\hline
\end{tabular}

\section{Self-attenuation correction}

When a transmission measurement is not available, the solution approach to self attenuation is the most accurate. The analytical calibration curve as described previously is shown in Figure 5 along with the

\footnotetext{
${ }^{11}$ See reference 5 .

${ }^{12}$ See reference 5 .
} 
linear area calibration with no self attenuation correction. Both the erroneous result of $170 \mathrm{~g}$ using virtually no self attenuation correction and the result if self attenuation had been applied are shown in the figure.

A background was measured and corrected for the filter housing. A deficiency in the traditional GGH approach to self attenuation is that background is not corrected for attenuation by the uranium material. This deficiency has been addressed by $\mathrm{Y}-12 .^{13}$ In the case of the 8 by 8 by 6 in filter, the transmission was about $1 \%$. Therefore no background is detected.

When a geometry correction of 1.8 is applied to the count rate, the result becomes infinite. Using a more modest correction of 1.54 a result of $1.7 \mathrm{~kg}$ is obtained. This value is shown on the calibration curve in Figure 5. A geometry correction of modest magnitude can have a dramatic impact on the result when the effects of self attenuation are also taken into account.

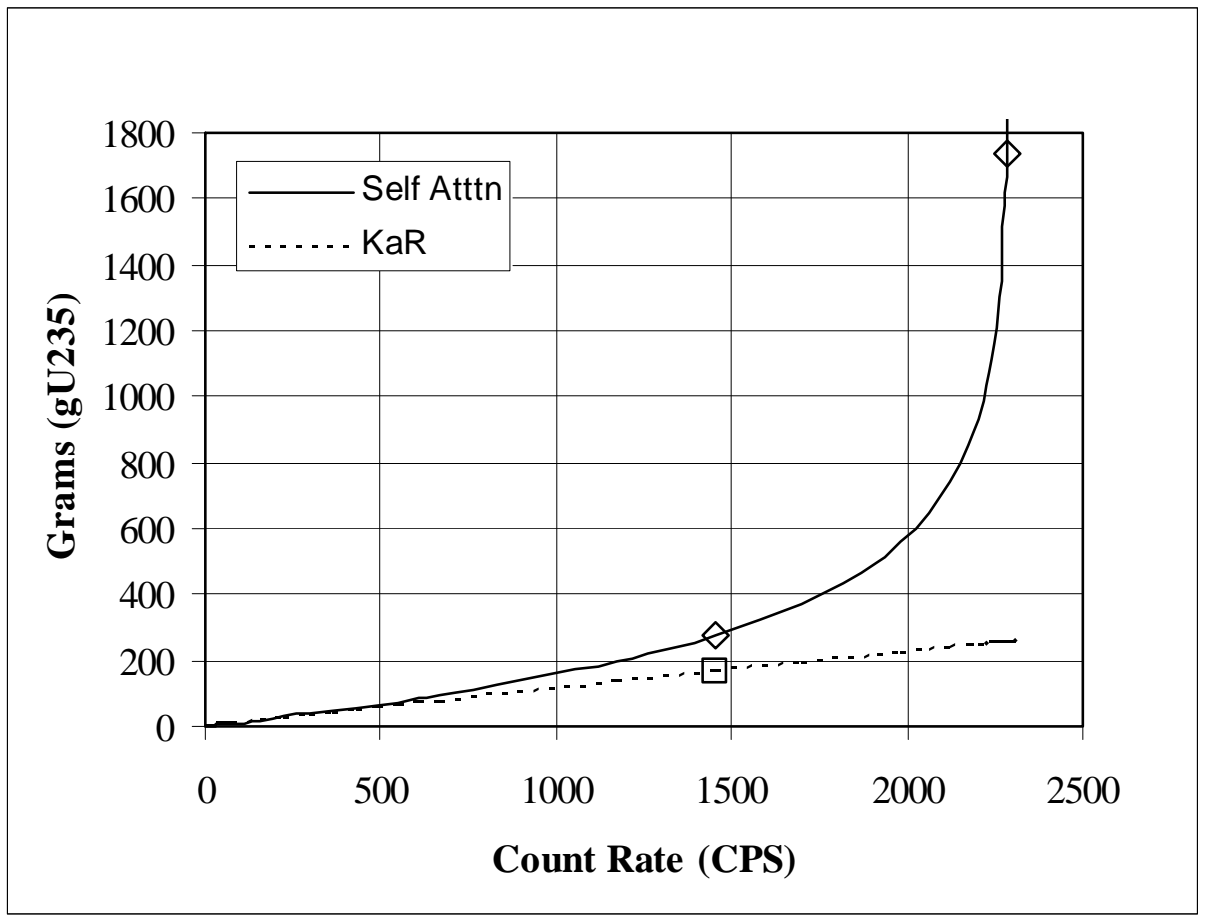

Figure 5. Analytical calibration and results of the June measurement of the 8 by 8 by 6 inch HEPA filter.

\footnotetext{
${ }^{13}$ R. B. Oberer, C. A. Gunn, L. G. Chiang, "Improved Background Corrections for Uranium Holdup Measurements," Document No. Y/DK-2107 (June 2004).
} 
Table 5. Analytical calibration and results of the June measurement of the 8 by 8 by 6 inch HEPA filter.

\begin{tabular}{|l|c|c|c|r|r|r|}
\hline $\begin{array}{l}\text { Area } \\
413 \mathrm{~cm}^{2}\end{array}$ & $\begin{array}{c}\text { Calibration } \\
\left(\mathrm{sec} \cdot \mathrm{g} / \mathrm{cm}^{2}\right)\end{array}$ & $\begin{array}{c}\text { Net Rate } \\
(1 / \mathrm{sec})\end{array}$ & $\begin{array}{c}\mathrm{KaR} \\
\left(\mathrm{g} / \mathrm{cm}^{2}\right)\end{array}$ & $\begin{array}{c}\text { Self Atten } \\
\text { Correction }\end{array}$ & $\begin{array}{c}\text { Density } \\
\text { Thickness } \\
\left(\mathrm{g} / \mathrm{cm}^{2}\right)\end{array}$ & $\begin{array}{c}\text { U-235 } \\
(\mathrm{g})\end{array}$ \\
\hline $\begin{array}{l}\text { No Self } \\
\text { Atten }\end{array}$ & $2.699 \mathrm{E}-04$ & & & & \\
\hline $\begin{array}{l}\text { HMS 3 } \\
\text { Revised }\end{array}$ & & 1456 & 0.3930 & 1.06 & 0.4166 & 172 \\
\hline $\begin{array}{l}\text { Calibration } \\
\text { No } \\
\text { background }\end{array}$ & & 0.3930 & & 0.5607 & 231 \\
\hline $\begin{array}{l}\text { Calibration, } \\
\text { Geometry } \\
\text { Correction }\end{array}$ & & 1483 & & & & \\
\hline
\end{tabular}

In August the filter was removed and replaced with a new HEPA filter. The original filter was measured on an SGS against a filter standard. The result of the SGS measurement was 780. Several more measurements using the solution approach to self attenuation were also performed subsequently with comparable results from the SGS.

The filter was measured again in August 2005 on both the SGS and by holdup measurement techniques after $1.7 \mathrm{~kg}$, of $0.8373 \mathrm{gU} / \mathrm{g}, 93.146 \%{ }^{235} \mathrm{U}$ material was shaken out. The result of the SGS measurement was $444 \mathrm{~g}^{235} \mathrm{U}$ and the result of the holdup measurement was $391 \mathrm{~g}$.

In August, the replacement filter was measured in place. This time the detector was positioned in contact with the 8 by 6 inch side. The result of the holdup measurement was $102 \mathrm{~g}{ }^{235} \mathrm{U}$. The replacement filter was also removed and measured on the SGS with a result of 78g.

\section{Conclusion}

In addition to analytical uncertainty, sampling and modeling uncertainty are large contributors to holdup uncertainty. The variation in the holdup measurement results for the 24 by 24 by 12 inch HEPA filter is within $20 \%$ even with widely varying models. This measurement probably represents the minimum real world uncertainty. The measurement of the 8 by 8 by 6 inch HEPA filter, on the other hand, represents a more extreme situation. It is however not the worst case scenario. At least the construction of the filter is well known. Many holdup scenarios involve measurements of less well known equipment. In these cases there will always be a risk of missing large quantities of material. 